\title{
Collaborative Governance in Off-site Anoa Conservation at The Anoa Breeding Center of The Manado Environment and Forestry Research and Development Institute
}

\author{
Bambang Subatin ${ }^{1}$ \\ Agus Pramusinto ${ }^{2}$
}

\begin{abstract}
Collaborative governance has, currently, become an alternative to resolving public issues, wherein the government is suggested to collaborate with cross-sector organizations. Although several collaborative efforts developed by the government were reported to have failed, there are a number of successful collaborations established to resolve various issues. The main objective of this study is to analyze why did the collaboration process of the off-site anoa conservation through the Anoa Breeding Center (ABC) succeed in increasing the anoa population. This study employed the qualitative descriptive methodology. The data collection techniques used were literature study, observation, and interviews with stakeholders involved in ABC activities. The study results show that the collaboration in managing $A B C$ was successful and it effectively resolved the problems confronted in the off-site anoa conservation due to active role of the administrators in realizing extensive participation, establishing and maintaining trust, as well as running a transparent process among the actors. The established collaboration is supported by a leadership that facilitated the implementation of the collaboration process. The collaboration is carried out formally as stipulated in the MoU made, as well as informally on the basis of the trust developed. The determining factors in the success of the collaboration in the off-site anoa conservation at $\mathrm{ABC}$ are the presence of process transparency, clear basic values, scope of actors involved, and facilitative leadership in the collaboration effort.
\end{abstract}

\section{Keywords:}

anoa; anoa breeding center; collaborative governance; collaboration; ex-situ conservation

\section{Introduction}

This study analyzed the success of collaborative governance in addressing issues in the field of conservation. Specifically, this study took the case of anoa conservation at Anoa Breeding Center (ABC) in Manado, North Sulawesi. The key argument in this paper is that the success of collaborative governance is greatly determined by the active role of $\mathrm{ABC}$ as the program manager in developing extensive actor participation, a transparent process, and trust among actors.

There are quite a lot of studies relating to collaborative governance, particularly in developed countries. Experts have conducted studies on how collaborative governance

\footnotetext{
${ }^{1}$ Environment and Forestry Research and Development Center Manado Email: bams.mapugm@gmail.com

${ }^{2}$ Head of Department of Public Policy and Management, Faculty of Social and Political Sciences, Universitas Gadjah Mada

Email: agus.pramusinto@ugm.ac.id
} 
functions in Europe, America, and Australia. These studies were done using various cases. A few examples are studies of collaborative governance with variance in the environmental field (Francesch-Huidobro, 2015), the social field (Ramadass, Sambasivan, \& Xavier, 2018), the field of natural resources and water management (Connick, 2006; Head, Ross, \& Bellamy, 2016), climate change (Baird, Plummer, \& Bodin, 2016), and disaster management (Bang \& Kim, 2016).

Cross-sector collaboration has recently become a topic of study in public management, wherein governments are suggested to collaborate with cross-sector organizations and civil society to address public issues they are unable to tackle alone (Kettl, 2015). The various forms of collaborative efforts carried out by the government and nongovernment stakeholders to address public issues may be considered as a form of collaborative governance (Ansell \& Gash, 2008; Bryson, Crosby, \& Stone, 2006, 2015; Emerson, Nabatchi, \& Balogh, 2012; Thomson \& Perry, 2006).

The above definition also explains that the form of collaboration conducted by governments, the interaction with various actors from the government, the private sector, and the public, either directly or indirectly, are consequences of public administration. A number of experts have stated that integration through collaborative governance will create partnership to produce more valuable goods/ services than those that are individually made (Fyall \& Garrod, 2005).

Reflecting on the collaborative governance practices developed in the sample cases above, the collaborative approach has also been implemented in Indonesia, in which one of them is to address problems in the field of conservation. The problem particularly relates to the declining wildlife population in their natural habitat, especially the anoa. Based on data released by the Convention on International Trade in Endangered Species
(CITES) in 2017, there are approximately 800 species listed in Appendix I (most endangered species) the world over. Whereas in Indonesia, there are over 200 species listed in Appendix I category, in which one of them is anoa (bubalus sp.).

Anoa is a small ox endemic to the island of Sulawesi, which is categorized as an endangered species and has been on the brink of extinction since the 1960s. In the last decade, its population has been drastically declining. It is estimated that no more than 5,000 anoas are living in the wild today (Semiadi, Burton, Schreiber, \& Mustari, 2008). According to an IUCN report, in 2008 the anoa population in Sulawesi was less than 2,500 and they were spread out throughout the entire forest areas of the Sulawesi landmass. Meanwhile, based on 2017 statistical data report made by the Directorate General of Natural Resources and Ecosystem Conservation (Direktorat Jenderal Konservasi Sumber Daya Alam dan Ekosistem Ditjen KSDAE) of the Ministry of Environment and Forestry (Kementerian Lingkungan Hidup dan Kehutanan - KLHK) obtained from 13 observation sites, the anoas observed merely amounted to 387.

One of the causes of the declining anoa population in the wild was the social behavior of people who frequently hunt them for their hide, antlers, and meat. Additionally, the destruction of their natural habitat due to the exploitation of forest areas also became the main cause of the declining anoa population in the wild (Burton, Hedges, \& Mustari, 2005).

The protection of anoas on a world scale has been conducted by having them listed in the endangered species category by the International Union for conservation of Nature (IUCN) and CITES. Anoa is listed in Appendix I, which means that the species is protected and its sale for commercial purposes is prohibited. The Indonesian government has also taken preventive measures. One of the government's efforts to protect anoa from 
extinction is by issuing Law No. 5/1990 on the Conservation of Biological Natural Resource and Its Ecosystem. This effort was further reinforced with Governmental Regulation No. 7/1999 on Preserving Flora and Fauna Species, in which the anoa is included as a protected priority species along with banteng and babirusa. However, these measures were still deemed unsuccessful as numerous anoas remained hunted and captured.

The Ministry of Environment and Forestry (KLHK) launched an effort of conducting offsite conservation by issuing Forestry Ministerial Regulation No. P.54/Menhut-II/2013 on the Action Plan and Strategy for the Conservation of Anoa (Bubalus Depressicornis and Bubalus Quarlesi) Years 2013-2022. The aim of this policy is to maintain stable anoa population up till the year 2022 and to protect the supporting habitat required through the implementation of a conservation program involving multiparty stakeholders in an efficient and effective manner.

The anoa conservation effort is also conducted off-site through the Anoa Breeding Center (ABC) at the Manado Environment and Forestry Research and Development Institute (Balai Penelitian dan Pengembangan Lingkungan Hidup dan Kehutanan - BP2LHK), which was initiated in 2008. The off-site or exsitu conservation began by conducting studies on the anoa's habitat (Arini \& Wahyuni, 2016) and its preferred diet (Arini \& Nugroho, 2016). Subsequently, in 2011, a collaborative effort was carried out by BP2LHK and the North Sulawesi Natural Resource Conservation Center (Badan Konservasi Sumber Daya Alam - BKSDA) in establishing an off-site anoa captivity. Their endeavor was marked with the construction of a temporary pen and the handover of 3 impounded anoas from the community by the North Sulawesi BKSDA. The first collaboration initiative between the Manado BP2LHK and the North Sulawesi BKSDA became the milestone for the founding of the off-site conservation in $\mathrm{ABC}$.
After operating for a period of around four years, the conservation efforts had not shown any result. The anoas in captivity had not produced any offspring. In fact, based on an interview with the deputy manager of the $\mathrm{ABC}$ Team and the press release issued by the Manado BP2LHK, some of the anoas were found dead, be it the newborns or the ones being raised. Failure in breeding the anoas was a result of a number of things of which among them was the lack of veterinarians who should be present daily to care for anoas, medicate them, and assist them in labor and delivery. Another issue concerned the capacity of anoa keepers and managers who did not have sufficient experiences to properly manage the anoas. Additionally, there were also issues relating to the lack of funds for constructing appropriate holding pens with proper facilities and animal clinic, and there was also the issue of a feeble management team which added to the long list of problems in managing $\mathrm{ABC}$.

In 2015, an idea was developed by the head of BP2LHK Manado to improve the performance of the Anoa Breeding Center (ABC), which began by officially launching $\mathrm{ABC}$ as a conservation center and establishing cross-sector collaboration. The collaboration is considered as a way to address the problems encountered at the off-site anoa conservation in $\mathrm{ABC}$. The Manado BP2LHK as the institution in charge of managing $A B C$ begin attempting to engage in collaborative partnership with the private sector to improve the facility and provide medical staff. Additionally, collaborations were also fostered with conservation institutions, universities, and the general public to jointly accomplish the aim of making a better conservation center.

The collaborative efforts created substantial changes in the management of the off-site anoa conservation in ABC. This can be observed from the population growth of anoas raised in $A B C$, which increased, following the collaborative partnerships fostered with the parties involved. 
Table 1.

Data of Anoa Development at ABC of BP2LHK Manado from 2011 to 2018

\begin{tabular}{cccccl}
\hline Year & $\begin{array}{c}\text { Year-in Anoa } \\
\text { Population }\end{array}$ & Plus & Minus & $\begin{array}{c}\text { Year-out Anoa } \\
\text { Population }\end{array}$ & \multicolumn{1}{c}{ Annotation } \\
\hline 2011 & 0 & 3 & - & 3 & Initial handover \\
2012 & 3 & - & - & 3 & No addition \\
2013 & 3 & 1 & - & 4 & Added from impound \\
2014 & 4 & 1 & 1 & 4 & Added from impound \& one died \\
2015 & 4 & 3 & 1 & 6 & Added from impound \& gave birth but died \\
2016 & 6 & 1 & - & 7 & Added from handover by the community \\
2017 & 7 & 2 & - & 9 & Addition by birth \\
2018 & 9 & 1 & - & 10 & Addition by birth \\
\hline
\end{tabular}

Source: Processed ABC Data Report, 2018

The table of anoa population development at $\mathrm{ABC}$ above indicates that the anoas were successfully bred starting in 2016 following collaborative efforts with the private sector, conservation institutions, and the public. In a period of three years after the cross-sector collaboration was initiated, $\mathrm{ABC}$ had succeeded in breeding anoas naturally. There were 3 baby anoas delivered through the facility. This success is proof that the collaborating parties have a strong commitment to ensure the success of the anoa conservation program. The scope of the parties involved in the collaboration has also become more expansive. Given their achievement, more parties intend to collaborate and lend a hand in making $A B C$ more successful.

The success of breeding anoa is ABC's main asset for accomplishing other achievements in 2018. ABC has currently passed the selection process as one of the nominees for a leading center of science and technology (Pusat Unggulan Iptek - PUI) in the field of conservation. ABC is undergoing the final assessment process determining it as a PUI by the Ministry of Research and Higher Education.

Such achievement is inseparable from the collaborative efforts established by the stakeholders involved. $A B C$ is a collaborative model that utilizes a government-centered model wherein BP2LHK Manado functions as the initiator and main actor responsible for managing the anoa breeding activities. In line with Clarke (2017), government-centered collaborations are more sustainable than the community-based collaboration model since this collaboration model has stronger relations among the actors given that there is a formal agreement in place.

In the last few decades, scholars have continued to highlight cases of successful cross-sector collaborations, but many have also reported cases that failed and unequal results (Andrews \& Entwistle, 2010; Hodge \& Greve, 2007). Previous studies on collaborative governance have also concluded that collaborative governance has garnered numerous success in addressing complex issues (Connick, 2006; Cradock-Henry, Greenhalgh, Brown, \& Sinner, 2017; de Koning et al., 2017), however, there have also been many cases of failure found (Bang \& Kim, 2016; Thompson, 2008). According to de Koning et al., (2017) a successful collaborative government arrangement is capable of developing certain conditions that encourage public engagement, formal mechanism of power distribution, ownership of local resources based on customary rights, top-down accountability, trust building mechanism, and adaptive approach for assessing performance and improvement.

Research results by Knobloch (2016) explain that although there are numerous 
cases of successful collaborative governance, what they have essentially achieved was merely at the planning stage. Meanwhile, research by Bang and Kim (2016) suggests that the relationship among the organizations involved in the collaboration needs to be formalized and its implementation process should be made flexible/adaptive particularly in terms of planning and implementation of the collaborative institutional framework. According to results of study conducted by Belton and Smith (2010), the success of collaborative governance may be determined by the presence of a neutral facilitator among the existing groups in the collaboration.

Successful collaboration implemented by the government requires incentives from the community as well as political support (de Koning et al., 2017), public awareness and talented leadership is necessary (Singleton, 2002). There have been copious studies discussing collaboration as a means to mitigate impacts from the destruction of surrounding nature (Head et al., 2016), environmental degradation (Baird et al., 2016), and, more specifically, the destruction of the forest as a habitat for the wildlife depending on them (de Koning et al., 2017). However, in the field of conservation, off-site or ex-situ conservation is still rarely conducted. Therefore, the idea of establishing collaborative governance by involving multiple parties in addressing this problem is a crucial issue (Baird et al., 2016; Head et al., 2016).

Based on the explanations in the above passages, the objective of this research is to describe how the collaborative governance process established through the off-site anoa conservation program at the anoa breeding center (ABC) was able to successfully increase the anoa population.

\section{The Concept of Collaborative Governance}

The term collaborative governance has developed in the last few decades as a new concept of governance. Many experts have offered collaborative governance as a new concept in formulating and implementing public policy by involving stakeholders from the government, the private sector, and the public to jointly collaborate in the process of decision-making by consensus. The involvement among stakeholders requires a process to build trust, develop common understanding of issues through deliberations, develop resources, capacity, and leadership to support collaborative efforts (Ansell \& Gash, 2008; Bryson et al., 2006, 2015; Emerson et al., 2012).

Thompson and Perry (2006) revealed that collaboration is a process in which autonomous actors engage in interactions through formal and informal negotiations, create common rules and structure that regulate their relations and code of conduct to determine what issues or problems lead them to collaborate. Meanwhile, Ansell and Gash (2008) define collaborative governance as a form of government arrangement in which government actors directly involve nongovernment stakeholders or actors in the process of a joint decision-making in a formal manner, consensus-oriented, and consultatively with the objective of drafting or implementing public policies or managing the operation of public programs or public assets.

Emerson et al. (2012) define collaborative governance broadly as the processes and structures of public policy decision making and management that engage people constructively across the boundaries of public agencies, levels of government, and/or the public, private and civic spheres in order to carry out a public purpose that could not otherwise be accomplished.

Donahue and Zeckhauser (2004) define collaborative governance as a form of collaborative relationship between the government as regulator and the private sector as implementer. Collaborative governance may 
have either broad or narrow definitions. There are eight dimensions mentioned by Donahue and Zeckhauser (2004) to identify collaborative governance, namely: formality; duration; focus; institutional diversity; "valence"; stability versus volatility; initiative; and problem-driven versus opportunity-driven.

Referring to the various definitions presented by many experts on collaborative governance, it can be explained that, essentially, the need to establish collaboration emerges due to a common problem and mutual dependence among the actors. Collaborative governance may be described as a process involving nongovernment institutions with mutually beneficial interaction among the actors. By using the perspective of collaborative governance, problems can be addressed and the positive goals of the respective parties achieved.

\section{The Collaborative Governance Model}

An integrative framework provides a description of the aspects involved in the collaborative governance process beginning from the preconditions, process, and up till post process. Ansell and Gash (2008) present a collaborative governance model consisting of four key variables, namely starting conditions, institutional design, facilitative leadership, and outcomes. The collaborative process covers face-to-face dialogue, trust building, commitment to process, shared understanding, and intermediate outcomes. All collaborative governance is established through face-to-face dialogues among stakeholders. As a process established via consensus, dialogue is much required by stakeholders to identify the shared benefits and opportunities. The collaborative governance model presented by Ansell and Gash (2008) is shown in Figure 1.

From the figure above, collaborative governance is shown as a circular process instead of a linear one. The institutional design aspect presented by Ansell and Gash (2008) includes participation inclusiveness, forum
Figure 1.

Collaborative Governance Model

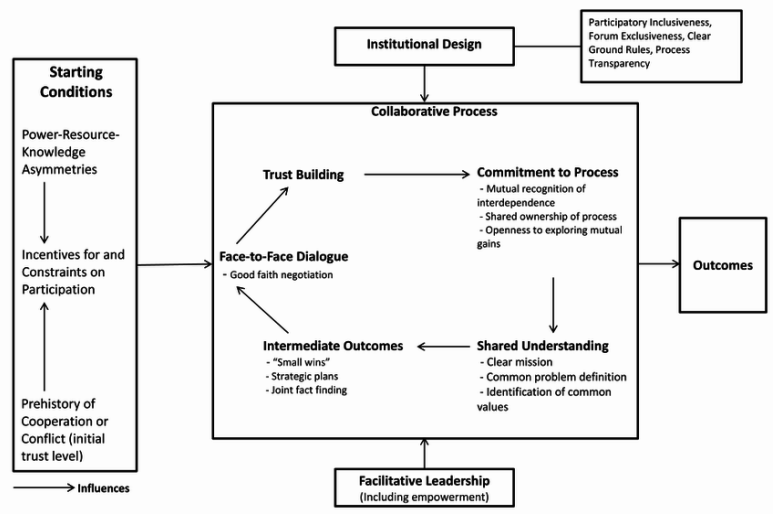

Source: Ansell and Gash (2008)

exclusiveness, clear ground rules, and process transparency.

Meanwhile, according to Emerson et al. (2012), the integrative framework for collaborative governance has a few differences with the model presented by Ansel and Gash (2008). The model of collaborative governance proposed by Emerson et al. (2012) can be observed in Figure 2 below:

Figure 2.

\section{Integrative Framework for Collaborative} Governance

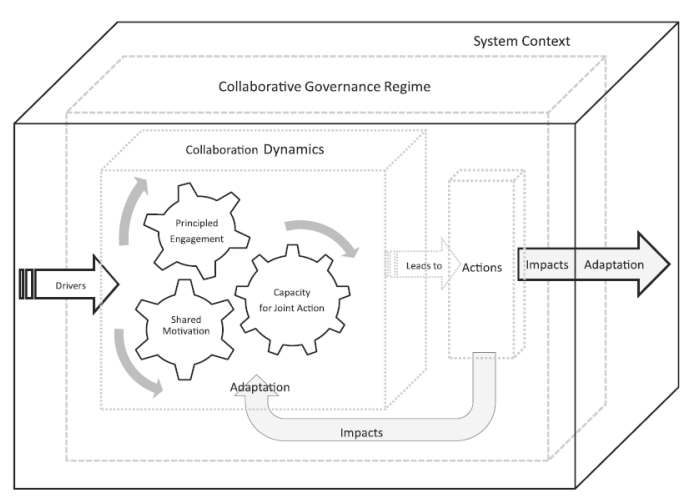

Source: Emerson et al. (2012)

Emerson et al. (2012) describe the integrative framework for collaborative governance in the form of three dimensional netting. The first box represents the general system context, the second box represents the 
collaborative governance regime (CGR), while the third box represents actions and dynamics of collaborative governance. The outer box with bold lines represents surrounding system context which consists of politics, law, socioeconomy, environment, and other influences, the system context may affect and be affected by the collaborative governance regime. The system context generates opportunities and threats that influence collaboration dynamics, which drives and triggers the emergence of leadership, motivation, mutual dependency, and uncertainty directing the collaborative governance regime.

According to Emerson et al. (2012), collaboration dynamics is an interactive process, which is in line to what Ansell and Gash (2008) mentioned. There are three interactive components in collaboration dynamics, which are: principled engagement; shared motivation; and capacity for joint action. Principled engagement concerns the finding, defining, deliberating, and determining processes. Shared motivation comprises of trust, common understanding, internal legitimacy, and shared commitment. Whereas capacity for joint action involves institutional and procedural arrangements, leadership, knowledge, and resources.

\section{Actor Collaboration Process}

According to Kim, (2016), the collaboration process is defined as an interactive and circular process among its components. Furthermore, according to Ansell and Gash (2008), the collaboration process consists of 5 (five) components, namely: dialogue; trust building; commitment to process; shared understanding; and intermediate outcomes. Meanwhile, according to Emerson et al. (2012), the components of the collaboration process include principled engagement, shared motivation, and capacity for joint action. The components of shared motivation are: shared trust; common understanding; internal legitimacy; and shared commitment.
To describe the collaborative governance process taking place in the management of $\mathrm{ABC}$, a combination of the collaborative process presented by Ansell and Gash (2008) and Emerson et al. (2012) was employed. The components in the collaboration process utilized as tools of analysis were: dialog; trust building; internal legitimacy; and shared commitment. The interaction among the components of the collaborative process can be seen in further detail in the following figure:

Figure 3.

\section{Combination of Collaborative Process among Actors}

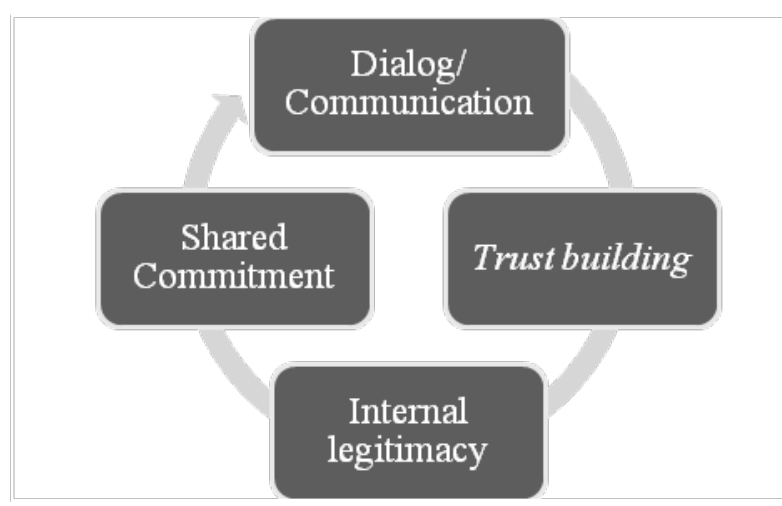

Source: Ansell and Gash (2008) and Emerson et al. (2012) as processed by the authors

Based on the figure above, we agree with Ansell and Gash (2008) that dialogs are required to start collaboration. In the next stage, we agree with Emerson et al. (2012) wherein the dialogs among stakeholders involved should be followed by trust building. Once trust is established among the stakeholders involved, the next stage would be internal legitimacy, and ultimately followed by establishing a joint commitment.

Every collaboration process requires dialogs or communication among the parties involved. Ansell and Gash (2008) explain that dialog is an essential process to break down the walls of stereotype and obstacles in communicating with fellow stakeholders involved. Although in a number of cases, 
dialog may reinforce stereotype among the participants, dialogs are crucial in building trust, mutual respect, establishing shared understanding, and building commitment in the collaboration process.

Emerson et al. (2012) explain that trust should be present over a long period of time in the collaboration process. Trust building is an effort carried out perpetually so long as the participants are involved in the collaboration process. The trust established among the participants can be utilized as an instrument to spare transaction costs, increase investment, stabilize relations among the members involved, and exchange information, knowledge, and information.

According to Emerson et al. (2012), internal legitimacy refers to the confirmation and validation that the stakeholders involved in the collaboration are trustworthy, credible, have relatively common interests, and are mutually dependent, which legitimizes and motivates sustainable collaboration. Such legitimacy is a result of common understanding shared among the stakeholders involved.

According to Ansell and Gash (2008), commitment is a vital aspect in the process of collaboration among the parties involved. Commitment is closely associated to the basic motivation of the members involved in the collaboration. Additionally, commitment to the process implies that they have agreed in goodwill that acquiring shared benefits is the best means to achieve the desired outcome. Subsequently, Emerson et al. (2012) explain that a shared commitment will enable the stakeholders involved to go beyond the organizational, sectoral, and/or jurisdictional boundaries that had previously separated them.

\section{Determining Factors in the Success of Collaborative Governance}

The success of collaborative governance, according to most literature, can be assessed from the perspective of its process and outcome (Head, 2008; Provan \& Kenis, 2008; Ran \& Qi, 2017). Furthermore, according to Head (2008), the criteria for collaboration effectiveness include the matter of process which covers institutional continuity, network growth, interaction among members, services coordination, and the matter of outcome at several levels of services. Whereas according to Ran and Qi (2017), it is explained that the effectiveness/success of collaborative governance may be examined through the following perspectives:

1. The extent to which the collaboration can obtain and maximize required resources as network input.

2. The degree of the intended network-level outcomes achieved by the collaborative efforts.

3. The process of building collaborations toward achieving network-level outcomes.

4. Satisfaction of the stakeholders involved.

According to Ansell and Gash (2008), the success of collaborative efforts can be determined by the leadership and institutional design. In order to explain the determining factors in the successful collaboration observed in the management of $A B C$, this study used the leadership and institutional design concept presented by Ansell and Gash (2008).

Ansell and Gash (2008) mention that institutional design refers to agreement and fundamental rules of collaboration that are crucial to the legitimacy procedure and collaboration process. The institutional design is a factor that determines the success of collaborations. Institutional design comprises of several components, namely: participatory inclusiveness; forum exclusiveness; clear ground rules; and process transparency.

The first factor, according to Ansell and Gash (2008), that determines successful collaboration is participatory inclusiveness. Collaboration can succeed given that there 
are more stakeholders involved with the same issue in a collaboration. Not involving certain individual/group that has a stake in the same issue may threaten and undermine the legitimacy of the collaboration process. Therefore, all relevant participants should be identified and involved in the collaboration to address a common issue.

The second factor is forum exclusiveness. Ansell and Gash (2008) explain that forum exclusiveness means that a collaboration forum should as much as possible be the only forum for addressing a common issue in the area. If the collaboration is the only forum in the area, then it would be easier to convince and motivate the parties involved to collaborate. This factor correlates with the previous factor, which is participatory inclusiveness. If there were actors not included that have the capacity to establish their own forum as an alternative, then their presence may threaten the effectiveness of collaboration. If there was another similar type of collaborative forum, then some actors may choose to join other forums that they believe is more fitting and appropriate as well as provide greater benefit for them.

The third factor is clear ground rules and process transparency. Ansell and Gash (2008) state that these two factors are crucial in the procedural legitimacy framework and in building trust. Mutually agreed upon fundamental rules that are implemented clearly and consistently will convince the parties involved in the collaboration that the collaboration can function in a fair, equal, and open manner. Additionally, process transparency will convince the parties involved that dialogs and negotiations are real, since the collaboration process disallows any backroom deals for the interest of one or few stakeholders.

The fourth factor is facilitative leadership. Ansell and Gash (2008) mention that leadership is a vital element in directing the participants to engage in collaborative efforts. According to Chrislip and Larson 1994; Ozawa 1993;
Pineawa, Warsh, and Maluccio 1998; Reilly 2001; Susskind and Cruikshank 1987 as cited in Ansell and Gash (2008), it is elaborated that facilitative leadership is essential in uniting stakeholders and getting them involved in collaborative efforts. Vangen and Huxham (2003) argue that leaders should often intervene by using more guided means to form an agenda in order to enhance collaboration.

Leadership is vital in determining and maintaining clear ground rules, building trust, facilitating dialogs, and exploring shared benefits. Vangen and Huxham (2003) opine that leadership is important for embracing, empowering, and involving stakeholders and then for mobilizing them to enhance collaboration. Experts state that collaborative governance requires a particular kind of leadership. Ryan (2001) as cited in Ansell and Gash (2008), for instance, identified three components of effective collaborative leadership: able to manage the collaboration process, maintain technical credibility and ensure that collaboration is utilized to make credible and convincing decisions so that it can be accepted by all stakeholders.

Lasker Weiss and Miller (2001) argue that collaborative leader should have the skills to (1) promote active and broad participation, (2) ensure extensive influence and control, (3) facilitate group productivity dynamics, and (4) expand the scope of the process. Successful collaboration may also involve many leaders, both formally and informally, rather than depending upon a single leader (Bradford, 1998; Lasker et al., 2001).

\section{Methods}

This research employed the qualitative approach with the location of study at the Anoa Breeding Center of the Manado Environment and Forestry Research and Development Institute that is stationed in the Kima Atas Sub-District, Mapanget District, Manado Municipality, North Sulawesi Province. The 
respondents in this research were individuals directly involved in the management of the Anoa Breeding Center in BP2LHK Manado. The technique used in selecting the respondents was purposive sampling. This study gathered two types of data, which are primary and secondary data. The data collection techniques used were literature study (desk research), observation, and interviews pertaining to the management of $\mathrm{ABC}$. The collected data included data of the actors involved, the process of collaboration building among the actors, and determining factors in the successful collaboration of managing ABC. Data were validated by using triangulation technique. Data acquired from a source was crosschecked with other sources, and the obtained data was subsequently analyzed in a descriptive qualitative manner.

\section{Results and Discussion}

Identification of Actors and Roles in the Collaborative Governance of $A B C$ Management

Every collaborative effort requires actors to be involved in joint actions. There are actors directly and indirectly involved in the management of anoas at ABC in BP2LHK Manado. Specifically speaking, the actors directly involved in the management of $A B C$ play crucial roles. In the following passages brief descriptions concerning the roles each actor involved in the collaboration of $\mathrm{ABC}$ management play are presented.

\section{The government}

The government is the key actor in leading the collaborative governance conducted in the off-site anoa conservation at $\mathrm{ABC}$. The government, which is represented by the Manado BP2LHK and the North Sulawesi BKSDA, has a vital role as the administrator of $\mathrm{ABC}$. In running $\mathrm{ABC}$ 's operational activities, Manado BP2LHK established an organization structure named the Anoa Breeding Center Team (ABC Team). The ABC Team is tasked to run anoa breeding related operational activities. The members of the ABC Team are mostly employees at Manado BP2LHK along with a veterinarian from the private sector and an anoa keeper from the community. Aside from assuming its main role, the government also plays a role in conducting research on anoa, making compost out of anoa manure, disseminating knowledge and information to schools, and receiving visiting guests from the community.

\section{The private sector}

Private actors have a substantial role to play in the ABC management collaboration. The private institutions directly involved in ABC management are PT. Cargil Indonesia, PT. MSN \& TTN, and PT. RJBMN. Without collaborative engagement of the private sector, the management of $\mathrm{ABC}$ would have been lacking and the breeding would not have run properly due to various existing obstacles. Based on observation data on the ground, the collaboration fostered with the private sector has been operational since 2015. The roles of the respective private actors involved in the collaboration vary as well. The role of the private sector, according to the study results, is to provide operational facilities, anoa pen, veterinarian, and conservation collaboration.

\section{The public}

The public actors playing a direct role in the management of $A B C$ remain limited. So far, members of the public involved in managing anoas have merely been limited to duties as anoa keepers. The ABC Team has involved the public to assist in cleaning the anoa pens, feeding the anoas, as well as foraging lush grass for feed. Additionally, fruits and vegetables for the anoas are also acquired through collaboration, although limited and informal, with traders who have become regular patrons. 


\section{International conservation institutions}

In addition to government, private, and community actors, international institutions, which are the Lepzig Zoo and GIZ from Germany, also play a significant role in enhancing the activities in ABC. GIZ and Leipzig Zoo lend their assistance by providing training to anoa keepers and $A B C^{\prime}$ 's management staff. Although the collaboration fostered is informal in nature, the role of Leipzig Zoo is crucial in enhancing the human resource capacity required for managing $\mathrm{ABC}$. Leipzig Zoo has provided training to the $A B C$ Team on how to treat and raise anoas according to the German standards.

\section{The Collaboration Process among Actors in the Management of $\mathrm{ABC}$}

The collaborative efforts undertaken in managing $\mathrm{ABC}$ is very important because by involving all the stakeholders, $A B C$ is able to successfully achieve the goal of anoa conservation. To get the collaboration process moving, dialog, trust, legitimacy, and shared commitment among the actors are necessary. AS argued by Ansell and Gash (2008) and Emerson et al. (2012), the collaboration made can be observed from the dialog/ communication among the actors, building and maintaining trust, internal legitimacy, and shared commitment in achieving a determined objective.

\section{Establishing dialog/communication among actors}

The Manado BP2LHK, which is the main actor in the management of $\mathrm{ABC}$, continuously established communication and dialogs among the actors involved. Communication was conducted to establish common understanding among the actors involved in the collaboration of managing $\mathrm{ABC}$. Communication between the administrators and actors involved was able to facilitate in forming a consensus. Hence, through communication, the stakeholders could obtain balanced information concerning the issues encountered.

Communication was also conducted by using both formal and informal media. Formally, the administrators carried out dialogs through official forums held by the administrators. Informally, communication among actors was done via various social media platforms such as WhatsApp, Facebook, YouTube, and Instagram. In the management of $A B C$, the administrators engaged in intensive communication efforts with all the actors. Communication was conducted to discuss and find solutions for problems that $A B C$ encountered.

There were meetings held among the collaborating parties, which usually took place during activities such as press conference on anoa birth, collaborative meetings, and seminar. Communication was also carried out directly by visiting partners intending to engage in collaboration. This was done by the administrators by visiting the potential partners' office or location.

Communication between the $\mathrm{ABC}$ administrators and the government, for example, was done to discuss issues relating to policies and regulations on conservation institution.

Communication with the private sector was carried out to discuss issues relating to budget limitation that the administrators must address to provide facilities, operational vehicle, and veterinarian that can monitor the anoas at all times. Additionally, communication was also done to discuss the continuity of the anoa conservation program and early conservation education.

The ABC Team often communicated and interacted with members of the community involved in managing $\mathrm{ABC}$. The communication largely concerned availability of feed for the anoas. Furthermore, communication with the public was also conducted by holding educational events in schools or through 
public visitations to the Anoa Breeding Center at Manado BP2LHK. Although it remained limited in those two areas, the established communication could help improve the performance of $\mathrm{ABC}$.

Communication with international institutions was carried out by the $A B C$ administrators in relation to enhancing the capacity of personnel managing $\mathrm{ABC}$. Communication with international institutions was conducted through the keeper and anoa breeding training held at $\mathrm{ABC}$ in Manado BP2LHK. In addition, communication was also done by responding to an invitation from the Leipzig Zoo, as $A B C^{\prime}$ s partner, to visit them in Germany.

\section{Establishing and maintaining trust in the collaboration}

The trust building process is conducted at all times as long as the actors are involved in the collaboration. Trust is of utmost importance in the collaboration of managing $\mathrm{ABC}$. The administrator as the main actor continuously establish and maintain trust in the collaboration so that $A B C^{\prime}$ 's activities run properly and sustainably. In addition, every actor involved in the collaboration has so far shown that they are trustworthy.

Building trust can be initiated by carrying out the responsibility shouldered by the respective actors involved. For example, being truly devoted in carrying out the commitment in accordance with the MoU agreed by the $\mathrm{ABC}$ Administrator, the government, and the private sector. PT Cargil Indonesia committed to providing assistance in the form of pens and veterinarians for $A B C$, and this has been provided according to the agreement. Meanwhile, the $A B C$ administrators are committed to maintain, care for, and conserve the anoas, which have been carried out by the administrators and proven by their success in breeding the anoas at ABC. Given that there are acknowledgements from the respective stakeholders as well as concrete evidences of what should be done and what outcomes should be achieved, a feeling of mutual trust will consequently grow among the actors involved in the collaboration.

Trust among the stakeholders is also maintained through the administrator's commitment in carrying out their duty and obligation of taking care of the anoas. The administrator continues to actively make reports of $A B C$ developments that include financial statement, anoa growth, progress of activities, and future plan. The reports are accordingly delivered to parties involved in the collaboration so they can acquire similar information concerning their collaborative efforts.

\section{Internal legitimacy}

Legitimacy is a continuation of building trust among the actors involved in the collaboration. The ABC administrator has taken measures to mobilize cross-sector collaboration. This is proven by their efforts in building trust and conducting intensive communication with all the stakeholders, by running the operation to the best of their ability in a consistent and continuous manner. Additionally, the administrator also has a good understanding of $\mathrm{ABC}^{\prime}$ 's objective, and they work wholeheartedly leading to their success in breeding the anoas. Hence, the actors involved are convinced that the $\mathrm{ABC}$ administrators can be trusted, have the required capacity, are credible, responsible, and have a noble interest in the collaboration fostered. The ABC administrators also believe that the other actors involved in the collaboration have the capacity, integrity, and are dependable for achieving the goal of the collaboration.

\section{Maintaining a shared commitment}

The $\mathrm{ABC}$ administrator and the actors involved have gone through the process of engaging in communication, building trust, 
and gaining legitimacy for quite a long period of time. The entire process has resulted in all the actors involved in the management of $\mathrm{ABC}$ to possess a strong shared commitment to run the activities of anoa conservation and achieve its goals. Thus, the commitment created in the collaboration of managing $\mathrm{ABC}$ is the result of a long process in establishing common values and mutual understanding among the actors. Consequently, the collaboration is not entirely fixated on formal collaboration agreements in the form of MoU or others.

The ABC administrators showed their commitment by consistently and routinely overseeing the anoa breeding operation, educating schoos and the public, and constantly improving their management, enhancing human resources capacity, and fostering collaborations with all stakeholders. Their commitment has resulted in positive outcome in breeding anoas at the center, which has made $\mathrm{ABC}$ as one of the leading centers for science and technology in the field of flora and fauna conservation. $\mathrm{ABC}$ is currently one of the anoa conservation centers recognized and appreciated by numerous parties, including those involved in the collaboration.

The ABC administrators also maintain their commitment by upgrading their skills and knowledge about off-site conservation. Keeper training and anoa breeding training activities facilitated by trainers from the Leipzig Zoo indicate their commitment to enhancing the ABC Team's capacity. Additionally, the $A B C$ Team often participated in workshops or conservation trainings held by other conservation institutions such as Taman Safari.

In addition to the strong commitment toward enhancing $\mathrm{ABC}$ Team's human resource capacity, the administrators are also willing to share their knowledge and experiences in breeding anoas to the public. The commitment of the $\mathrm{ABC}$ administrators in conducting anoa conservation activities is also shown by holding educational activities at schools.Such activities were held to provide understanding to students and the public on the importance of wildlife conservation, particularly anoas.

The ABC administrators always accepted visitations from guests wanting to know more about anoas. Many people visited ABC to see the anoas up close or to hold training and educational activities. Visitations were conducted by schools in the surrounding Manado area, as well as those from the private sector, NGOs, parliamentary members, and the general public. The commitment of $\mathrm{ABC}$ administrators to provide visitation services is constantly carried out by providing assistance and understanding regarding anoa breeding activities. This shows that the administrators' commitment in realizing and encouraging the collaboration process among the actors is very real and is maintained continually up till today.

\section{Determining factors in the collaboration of managing $\mathrm{ABC}$}

Ansel and Gash (2008) revealed that collaboration can properly function depending on a number of determining factors, which include process transparency, clear ground rules, scope of actors involved, and leadership that facilitates the collaboration.

Process transparency convinces every actor that all the dialogs and negotiations are real, the collaboration process does not allow backroom agreement practices for the personal/individual interest of one group. In the management of $\mathrm{ABC}$, the collaboration process operated in a transparent and open manner. Such transparency has resulted in establishing and maintaining trust among the actors involved in the collaboration. The collaboration in managing $\mathrm{ABC}$ involves the flow of goods and monetary values. The administrators always prepare and deliver their financial statements periodically to their partners as a manifestation of their responsibility in using the funds. 
Process transparency, for example, is observed in the relationship between the administrators and the private sector involved. The administrators constantly make a detailed record and convey their reports on the development of $A B C$, which includes report on the condition of the anoas, future activities, and achieved outcomes to their partners. The administrators are also open to any suggestions given by their partners concerning pen design, breeding center master plan, as well as drafting of the anoa conservation roadmap.

Clear ground rules that are consistently implemented will convince the stakeholders and ensure a fair, proportional, and open collaboration. There are a number of formal written rules concerning the collaboration in managing $\mathrm{ABC}$. These rules are stipulated in the collaboration agreement accepted by both parties. These formal rules set the basis for fostering collaboration between the government and the private sector. Additionally, there are no formal rules agreed in some of the collaborations fostered with the community and international institutions. Nevertheless, there are values of trust and honesty upheld by the stakeholders.

Scope of actors involved. A collaboration is successful when the scope of actors involved becomes more substantial and expansive in addressing the same problem. the collaboration in managing $A B C$ has involved numerous parties. There are those that are directly involved in managing the anoas and there are those indirectly involved in $\mathrm{ABC}^{\prime}$ 's operation. The stakeholders directly involved with ABC's operation are the Manado BP2LHK, North Sulawesi BKSDA, PT. Cargil Indonesia, PT. MSM TTN, PT JRBM, Leipzig Zoo, and community members working as anoa keepers.

Meanwhile, those indirectly involved in managing $\mathrm{ABC}$ but provide much needed support, among others, are the South Sulawesi BKSDA, Mr. Bogani Nani Wartabone, conservation institutions (Tasikoki, Taman
Safari Indonesia, Surabaya and Maros Zoos), universities (UNSRAT, IPB), Seameo Biotrop, and the general public. In addition, the involvement of the North Sulawesi Provincial Government is also essential, particularly in encouraging the public to participate in anoa conservation. Such participation encourages the public and regional governments to disseminate information on the importance of preserving anoas.

Facilitative leadership in the collaboration of manaing $\mathrm{ABC}$ is shown in the efforts made by the Head of BP2LHK since the start of the collaboration until today. The Head of Manado BP2LHK has facilitated actors from the government, the private sector, and the community to jointly create a draft of the roadmap for an anoa study center, form a forum for anoa observers, and initiae collaboration with the private sector.

The Head of the Manado BP2LHK also formed the ABC Team tasked in overseeing anoa conservation activities. This also ensures that the role of a leader facilitating the conservation efforts is truly present and real. This support is formally proven by the issuance of a decree concerning the ABC Team as of current, although the Head of Manado BP2LHK has changed several times.

Aside from initiating the formation of a collaborative forum among stakeholders, the leadership role is also apparent in the collaboration to improve the anoa holding pen facility and veterinarian availability. The Head of BP2LHK actively engages in collaboration with the private sector, which is indicated with the direct visit to PT. Cargil's office to discuss issues of anoa conservation and talk about the collaboration to be fostered.

\section{Conclusion}

$A B C$ is able to operate effectively and sustainably by using the government-centered collaboration model. The ABC administrators actively initiated and encouraged collaboration 
with various parties. The essential role of the $A B C$ administrators in overseeing $A B C^{\prime}$ s operation is much needed, particularly to maintain the established collaboration and expand collaborative efforts with other parties.

The administrators are the most active actors in terms of communication engagement with other actors. The administrators continue to undertake efforts in establishing and maintaining trust in the collaboration. The $A B C$ administrators actively seek credible partners willing to support the collaboration. The administrators also constantly conduct conservation activities, such as consistent and sustainable public dissemination of anoa conservation. The administrators ensure that all members in the ABC Team have sufficient capacity and understanding on the objective of the collaboration to manage $\mathrm{ABC}$.

Collaboration in $\mathrm{ABC}$ management is not only based on formal arrangements of collaborative agreement, $\mathrm{MoU}$, and other binding instruments, there are also informal arrangements based on trust, shared values, objectives, and interests of actors involved in the collaboration. As a result, the collaboration in managing $\mathrm{ABC}$ is able to run for quite some time, it is stable without any conflict. The findings in this research validate Clarke's (2017) argument that the governmentcentered collaboration model is more successful and sustainable due to the presence of formal ties. However, in practice, the $\mathrm{ABC}$ management collaboration indicates some differences, wherein the collaboration's success and sustainability are not only determined by formal arrangements since the informal collaboration observed made it easier for actors to work together and expand the scope of collaboration.

The collaboration fostered by the government in managing $\mathrm{ABC}$ is successful on account of a number of factors including process transparency, clear ground rules agreed upon and carried out by the actors involved, and facilitative leadership supporting the collaborative process among the actors.

\section{References}

Andrews, R., \& Entwistle, T. (2010). Does crosssectoral partnership deliver? An empirical exploration of public service effectiveness, efficiency, and equity. Journal of Public Administration Research and Theory: J-PART, 20(3), 679-701.

Ansell, C., \& Gash, A. (2008). Collaborative governance in theory and practice. Journal of public administration research and theory, 18(4), 543-571.

Arini, D. I. D., \& Nugroho, A. (2016). Preferensi habitat Anoa (Bubalus spp.) di Taman Nasional Bogani Nani Wartabone (Vol. 2, pp. 103-108). Paper presented at Seminar Nasional Masyarakat Biodiversitas Indonesia, Masyarakat Biodiversitas Indonesia.

Arini, D. I. D., \& Wahyuni, N. I. (2016). Kelimpahan tumbuhan pakan anoa (Bubalus sp.) di Taman Nasional Bogani Nani Wartabone. Jurnal Penelitian Kehutanan Wallacea, 5(1), 91-102.

Baird, J., Plummer, R., \& Bodin, Ö. (2016). Collaborative governance for climate change adaptation in Canada: experimenting with adaptive co-management. Regional Environmental Change, 16(3), 747-758.

Bang, M. S., \& Kim, Y. Y. (2016). Collaborative governance difficulty and policy implication: Case study of the Sewol disaster in South Korea. Disaster Prevention and Management, Vol. 25(2), 212-226.

Belton, L. R., \& Jackson-Smith, D. (2010). Factors influencing success among collaborative sage-grouse management groups in the western United States. Environmental Conservation, 37(3), 250-260.

Bradford, N. (1998). Prospects for associative governance: Lessons from Ontario, Canada. Politics E Society, 26(4), 539-573.

Bryson, J. M., Crosby, B. C., \& Stone, M. M. (2006). The design and implementation of cross-sector collaborations: Propositions from the literature. Public Administration Review; Washington, 66(S1), 44. 
Bryson, J. M., Crosby, B. C., \& Stone, M. M. (2015). Designing and implementing cross-sector collaborations: Needed and challenging. Public Administration Review, 75(5), 647-663.

Burton, J., Hedges, S., \& Mustari, A. (2005). The taxonomic status, distribution and conservation of the lowland anoa Bubalus depressicornis and mountain anoa Bubalus quarlesi. Mammal Review, 35(1), 25-50.

Clarke, S. E. (2017). Local place-based collaborative governance: Comparing statecentric and society-centered models. Urban Affairs Review, 53(3), 578-602.

Connick, S. (2006). The Sacramento area water forum: A case study. Working paper//Institute of Urban and Regional Development.

Cradock-Henry, N. A., Greenhalgh, S., Brown, P., \& Sinner, J. (2017). Factors influencing successful collaboration for freshwater management in Aotearoa, New Zealand. Ecology and Society, 22(2).

Donahue, J. (2004). On collaborative governance. Corporate social responsibility initiative Working Paper, 2.

Emerson, K., Nabatchi, T., \& Balogh, S. (2012). An integrative framework for collaborative governance. Journal of Public Administration Research and Theory, 22(1), 1-29.

Francesch-Huidobro, M. (2015). Collaborative governance and environmental authority for adaptive flood risk: recreating sustainable coastal cities: theme 3: pathways towards urban modes that support regenerative sustainability. Journal of Cleaner Production, 107, 568-580.

Fyall, A., \& Garrod, B. (2005). Tourism Marketing : A Collaborative Approach. New York: Channel View Publications.

Head, B. W. (2008). Assessing network-based collaborations: effectiveness for whom?. Public Management Review, 10(6), 733-749.

Head, B. W., Ross, H., \& Bellamy, J. (2016). Managing wicked natural resource problems: The collaborative challenge at regional scales in Australia. Landscape and Urban Planning, Special Issue Working with wicked problems in socio-ecological systems: More awareness, greater acceptance, and better adaptation, 154, 81-92.

Hodge, G. A., \& Greve, C. (2007). Publicprivate partnerships: An international performance review. Public Administration Review; Washington, 67(3), 545-558.

Kettl, D. F. (2015). The job of government: Interweaving public functions and private hands. Public Administration Review, 75(2), 219-229.

Kim, S. (2016). The workings of collaborative governance: Evaluating collaborative community-building initiatives in Korea. Urban Studies, 53(16), 3547-3565.

Knobloch, J. (2016). We Can Work it Out: Implementation and Collaborative Governance. US: Oregon State University.

de Koning, M., Nguyen, T., Lockwood, M., Sengchanthavong, S., \& Phommasane, S. (2017). Collaborative Governance of Protected Areas: Success Factors and Prospects for Hin Nam No National Protected Area, Central Laos. Conservation and Society; Bangalore, 15(1).

Lasker, R. D., Weiss, E. S., \& Miller, R. (2001). Partnership synergy: a practical framework for studying and strengthening the collaborative advantage. The Milbank Quarterly, 79(2), 179-205.

Provan, K. G., \& Kenis, P. (2008). Modes of Network Governance: Structure, Management, and Effectiveness. Journal of Public Administration Research and Theory: J-PART, 18(2), 229-252.

Ramadass, shilla D., Sambasivan, M., \& Xavier, J. A. (2018). Collaboration outcomes in a public sector: impact of governance, leadership, interdependence and relational capital. Journal of Management \& Governance, 1-23.

Ran, B., \& Qi, H. (2017). Contingencies of Power Sharing in Collaborative Governance. The 
American Review of Public Administration, 0275074017745355.

Semiadi, G., Burton, J., Schreiber, A., \& Mustari, A. (2008). Bubalus quarlesi (No. e. T3128A9613851). The IUCN Red List of Threatened Species 2008.

Singleton, S. (2002). Collaborative Environmental Planning in the American West: The Good, the Bad and the Ugly. Environmental Politics, 11(3), 54-75.

Thompson, D. F. (2008). Deliberative Democratic Theory and Empirical Political Science.
Annual Review of Political Science, 11(1), 497-520.

Thomson, A. M., \& Perry, J. L. (2006). Collaboration Processes: Inside the Black Box. Public Administration Review; Washington, 66(S1), 20.

Vangen, S., \& Huxham, C. (2003). Enacting leadership for collaborative advantage: Dilemmas of ideology and pragmatism in the activities of partnership managers. British Journal of Management, 14, S61-S76. 